Paper accepted for publication on Ageing \& Society [20 April 2021]. ISSN: 1469-1779.

\title{
Experiences of stigma and discrimination among people living with dementia and family carers in Brazil: Qualitative study
}

Authors: Déborah Oliveira' ${ }^{1}$, Fabiana da Mata ${ }^{1}$, Elaine Mateus ${ }^{2,3}$, Christine W. Musyimi ${ }^{4}$, Nicolas Farina ${ }^{5}$, Cleusa P. Ferri ${ }^{1,6}$, Sara Evans-Lacko ${ }^{7}$

\section{Affiliations:}

1. Universidade Federal de Sao Paulo (UNIFESP), Escola Paulista de Medicina, Department of Psychiatry, Sao Paulo, Brazil

2. Federação Brasileira das Associações de Alzheimer (FEBRAZ), Parana, Brazil

3. Universidade Estadual de Londrina (UEL), Applied Linguistics, Department of Modern Languages, Parana, Brazil

4. Africa Mental Health Research and Training Foundation, Research Department, Kenya

5. Centre for Dementia Studies, Brighton and Sussex Medical School, Brighton, United Kingdom

6. Hospital Alemão Oswaldo Cruz, Sao Paulo, Brazil

7. Care Policy and Evaluation Centre, London School of Economics, London, United Kingdom

Corresponding author: Déborah Oliveira. Universidade Federal de Sao Paulo (UNIFESP), School of Medicine, Department of Psychiatry. Sao Paulo, Brazil. Rua: Major Maragliano, 241. Vila Mariana, Sao Paulo, Brazil. CEP: 04017-030. Email: oliveiradc.phd@gmail.com

\section{Acknowledgement}

We are grateful to all the participants for their time and trust in sharing their experiences.

\section{Funding}

This study was funded by the UK Research and Innovation's Global Challenges Research Fund, through the Economic and Social Research Council (grant number ES/P010938/1).

\section{Conflict of interest}

The authors declare no conflict of interest. 
Paper accepted for publication on Ageing \& Society [20 April 2021]. ISSN: 1469-1779.

\begin{abstract}
This study aimed to understand stigma in relation to people living with dementia in Sao Paulo, Brazil. Critical Narrative Inquiry methodology was used. Semi-structured interviews were conducted between January and March 2020 with six people living with dementia and 15 family carers. Inductive and deductive techniques were used. The latter was informed by Link and Phelan's (2001) sociological theory of stigma. Dementia was commonly viewed by people living with dementia as part of ageing and carers reported low levels awareness about the condition. To avoid negative reactions from people, people living with dementia managed the negative views of dementia by minimising and normalising the condition, by expressing their ability to live an active life, and by emphasising the positive impacts of dementia in their lives. Fear of negative reactions appeared to lead to a selective disclosure of their diagnosis. Among carers, stigmatising attitudes coincided with a strong willingness to provide good care, to protect the person cared for, as well as to understand and validate their caring experiences, rather than to cause harm. In doing so, however, carers ended up depersonalising and infantilising people living with dementia, underestimating their capacities, demanding 'obedience', and restricting their freedom. There is a need to increase awareness about dementia and to provide support and training on person-centred care for carers in Brazil.
\end{abstract}

Keywords: stigma, courtesy stigma, discrimination, stereotyping, dementia, caregivers, Alzheimer's disease, qualitative research

\title{
Introduction
}

Dementia is a degenerative neuropsychiatric condition that affects nearly 50 million people worldwide and is considered a global health priority by the World Health Organization (ADI 2019; ADI 2015). Approximately $70 \%$ of all people living with dementia are in low- and middle-income countries (Prince et al. 2015). Cognitive changes due to dementia can lead to 
Paper accepted for publication on Ageing \& Society [20 April 2021]. ISSN: 1469-1779.

stigmatisation through negative stereotypes, prejudice, and discrimination (Herrmann et al. 2018; Nguyen and Li 2020). Stigma can shape the experiences of people living with dementia and is a powerful negative force against social citizenship (O'Connor et al. 2018).

The negative views of the public about dementia can be internalised by those who develop dementia, leading to feelings of being a failure or stupid (Ashworh, 2020). Stigma can strip people living with dementia of their dignity and self-esteem (Dementia Australia 2018; Swaffer 2014) as it can lead to depersonalisation through denial or dismissal of their personhood (Kitwood 2006). This can subsequently lead to concealment of symptoms and avoidance of diagnosis, treatment, and social interactions (Lopez et al. 2019), all of which result in social isolation (Lopez et al. 2019), delayed access to care (Lopez et al. 2019), and social injustice (Young et al. 2019). Stigma is a public health concern as it is a fundamental determinant of morbidity, mortality and social inequities within stigmatised groups (Hatzenbuehler et al. 2013). Despite these negative impacts, research on the experiences of stigma among people living with dementia and their family carers is scant globally (Fletcher 2019; Nguyen and Li 2020).

Several theories and conceptual frameworks have been proposed to characterise the social experience of stigma within the broader field of mental health research (Nguyen and Li 2020; Rüsch et al. 2005; Werner 2014). According to Phelan and Link (Link and Phelan 2001), stigma occurs when a label associated with a negative stereotype is attached to an individual characteristic (e.g. mental illness), causing people with such characteristics to be seen as separate from and lower in status than others, leading to discrimination and a loss of social status, and inequalities among the stigmatised group. For stigmatization to occur, power must be exercised, so that out-groups are kept 'down', or dominated/exploited; are kept 'in', to maintain social norms; and kept 'away', through avoidance (Link and Phelan 2014). This conceptualization was built on the renowned work of Goffman (Goffman 1963 p.3), in which stigma is considered an "attribute that is deeply discrediting" and that reduces 
Paper accepted for publication on Ageing \& Society [20 April 2021]. ISSN: 1469-1779.

the stigmatised "from a whole and usual person to a tainted, discounted one". With the addition of 'power' as a key element through which stigma occurs, Link and Phelan's definition brings additional possibilities for understanding how macro and micro factors might determine many individual life chances, having the potential to inform multifaceted multilevel interventions that could produce real social change (Link and Phelan 2001). Stigmatization is ideologically framed within cultures and is socially naturalized by dominant dementia narratives (Zimmermann 2017). There is less research conceptualising dementia-related stigma (ADI 2019), but studies have shown that loss of credibility and social isolation are key stigmatising issues faced by people living with this condition (Brossard 2017). Additionally, concealment and shame have been reported by family carers (Lopez et al. 2019).

A global survey on attitudes to dementia involving nearly 70,000 responses of members of the public, people living with dementia, family carers and health professionals from 155 countries (ADI 2019) found over $85 \%$ of respondents living with dementia said their opinion had not been taken seriously; around $40 \%$ of the general public thought doctors and nurses ignore people with dementia; between $35 \%$ in high-income and $57 \%$ in low- and middleincome countries reported being treated unfairly in dating and intimate relationships; and over $35 \%$ of carers globally reported hiding the diagnosis of a person with dementia (ADI 2019).

The number of people living with dementia in Brazil is unclear since the existing prevalence studies have not been conducted at a national level and the number of people who do not have a formal diagnosis is nearly $80 \%$ (Nakamura et al. 2015). A systematic review focusing on regional-level data found that estimates could vary between $5.1 \%$ and $19 \%$, and that dementia prevalence increased with age and was higher among women (Fagundes et al. 2011). Family members are the main caregivers of older people (living with or without dementia) in Brazil and nearly $94 \%$ of the care is provided at home (Giacomin et al. 2018a). 
Paper accepted for publication on Ageing \& Society [20 April 2021]. ISSN: 1469-1779.

In addition, older people's informal care workers are mainly women, with a mean age of 48 years, married, and who have very basic reading and writing skills (Giacomin et al. 2018b).

Dementia-specific formal support is nearly non-existent in Brazil, however universal coverage of health care is secured by law through a National Health System (SUS). Family carers can access free support services, such as carer psychosocial support meetings and training, through the Brazilian Federation of Alzheimer's Association (FEBRAZ 2019). Nevertheless, such services tend to be provided mostly in urbanized and high-income areas, meaning that people from poorer and rural areas often have limited access to support. There is no availability of respite services or financial benefits/social (security) protection for carers in Brazil.

Research on knowledge and attitudes related to dementia in Latin-American countries is limited (Farina et al. 2020; Ibanez et al. 2020). In Brazil, data on the public understandings of dementia are scarce - only a few quantitative studies have been conducted and have indicated the presence of stigmatizing views among the population (Alzheimer Disease International 2019; Blay and Peluso 2008; Blay and Peluso 2010). For instance, stereotypes, prejudice and discrimination related to Alzheimer's disease were observed in cross-sectional study conducted in São Paulo, with less years of education associated with a higher levels of stigma (Blay and Peluso 2010). Therefore, there is an urgent need for further research on dementia-related stigma in different contexts and cultures, particularly in Latin America (Nguyen and Li 2020).

\section{Aim and scope}

The overarching aim of this study was to explore stigma-related perceptions and experiences in relation to people living with dementia and family carers in Brazil. We investigated knowledge, attitudes and behaviours towards people living with dementia and 
Paper accepted for publication on Ageing \& Society [20 April 2021]. ISSN: 1469-1779.

carers, experiences of stigma and discrimination, local culture-specific idioms of stigma and discrimination.

\section{Methodology and methods}

This cross-sectional qualitative study was conducted as part of the multi-national research programme called STRiDE (Strengthening Responses to Dementia in Income Countries: www.stride-dementia.org) aimed at improving care, treatment, and support for people living with dementia and their families in seven middle-income countries, including Brazil. Ethical permission for this study was granted by the Research Ethics Committee of the London School of Economics and Political Science, and by the National Commission for Research Ethics (CONEP) in Brazil (CAAE: 12917019.3.0000.5505).

\section{Qualitative design and approach}

A critical narrative inquiry $(\mathrm{CNI})$ methodology was used. The $\mathrm{CNI}$ methodology is a qualitative research approach rooted in interpretative social sciences (Hickson 2016; McCormack 2000a; McCormack 2000b), useful for understanding complex and multifaceted issues, such as multicultural identities and stigma related to mental illness (Chase 2018; Mizock and Russinova 2015). The narratives collected reflect the participants' world and experiences, which in this study helped us explore and understand how people living with dementia and family carers construct meaning from their experiences, interpretations, and perceptions of stigma and discrimination in relation to dementia. Stigmatization is part and result of the construction of social perceptions that frame those meanings. The coconstructivist epistemology underpinning $\mathrm{CNI}$ supported the researchers to reflect upon participants experiences in relation to their context and period in time (Hickson 2016).

\section{Topic guide development}

Home-based, semi-structured interviews were conducted between January and March 2020. The interview topic guide was drafted by SEL and discussed with the project management 
Paper accepted for publication on Ageing \& Society [20 April 2021]. ISSN: 1469-1779.

team, including people living with dementia and family carers. The guide was then reviewed and translated by the local team to ensure it was relevant for the Brazilian context (Table 1).

\author{
<Insert Table 1 here $>$
}

\title{
Participants and recruitment
}

Key sociodemographic sample characteristics are described in Table 2. To take part, people living with dementia had to be in early to moderate stages of dementia (as per self-report or reported by a close family member) and be able to provide consent. Family carers had to be aged 18 and over and to be regularly providing unpaid care to, or supervising the care of, the person living with dementia. Potential participants were recruited by the lead author via social media (e.g. carer groups on Facebook) using digital flyers and short messages encouraging carers or people living with dementia to get in touch with the research team. Community centres and primary healthcare services were contacted, and information about the study was shared by health and social care professionals at carer meetings or during home visits to people living with dementia. When potential participants voluntarily got in touch with the researcher through telephone or electronic messages, the researcher then checked the eligibility criteria and sent information sheets electronically in advance. For those who were interested in taking part, the researcher then scheduled a meeting at the person's home, where questions were answered, the consent form was signed, and the interview was conducted.

\section{$<$ Insert Table 2 here $>$}

We respected all the ethical principles for research with human beings stated in the international declaration of Helsinki, including respecting confidentiality, anonymity, and participant wellbeing. All participants were informed that they had no obligation to answer any of the study questions and had they feel upset with any of them, the interview could be stopped, or they could withdraw from the study at any moment without any giving reason. 
Paper accepted for publication on Ageing \& Society [20 April 2021]. ISSN: 1469-1779.

The researchers contact details were given in the consent form and participants were reminded that they could contact the researcher, or the Research Ethics Committee, had they felt the research had any negative impact on their wellbeing at any moment. Except for one person with dementia (M22), who was fully independent, all other participants living with dementia received help from family members to read, understand, and decide terms of participation. The researcher was mindful of the person with dementia's capacity to consent and ensured that their willingness to participate was voluntary and maintained throughout the study. The researcher made contact in advance with the person with dementia and their trusted contact in the family to ensure the person had enough time and space to decide on participation. Every participant was informed that their participation was voluntary and that they were under no obligation to take part. People living with dementia were asked to repeat what they had understood about the terms of participation in the study and to confirm their willingness to be kept in the study after the interview had finished. Verbal consent was obtained again at the end of the interview. One person living with dementia was illiterate and had her son sign on her behalf. As we did not ask participants directly about their socioeconomic group, we categorised individuals based on their socioeconomic sector of residence, according to Marques et al., (2017).

\section{Data collection}

All interviews were conducted in Brazilian Portuguese by the lead author. On average, each individual interview lasted 45 minutes with family carers and 30 minutes with people living with dementia. After providing informed consent, participants answered a short sociodemographic questionnaire. Except for two participants (F8 and M22), all other participants living with dementia had their family carers interviewed in the study (F9, F13, $F 17$, and F19), whereas several family carers were interviewed without the participation of the person with dementia they cared for in the study $(F 1, M 2, F 3, F 4, F 5, M 6$, $F 7$, and F12). 
Paper accepted for publication on Ageing \& Society [20 April 2021]. ISSN: 1469-1779.

Only one participant (M22) was aware of their dementia diagnosis. Therefore, the interview schedule was adapted to each participant situation to ask questions that were less specific to the condition to try to understand the person's knowledge, experiences and attitudes towards dementia and its symptoms (e.g. perceived changes in health, relationships, and independence). When the participant confirmed experiencing a dementia-related symptom, such as memory loss, the researcher then asked further questions about that. The researcher also explored what participants knew about dementia or Alzheimer's disease and their attitudes towards people living with such conditions.

\section{Data analysis}

Interviews were transcribed verbatim in the original language (Brazilian Portuguese) by professional transcribers. The transcripts were the checked for accuracy against the original recordings by DO (Brazilian), who also conducted the data analysis in the original idiom. The other co-authors were involved in discussions throughout the analytic process (all Brazilians or fluent in Portuguese). Although DO is a registered nurse with experience in dementia research, this was the first work she ever conducted on stigma related to dementia.

Data analysis was undertaken separately for each group (people living with dementia and family cares) using the software NVivo ${ }^{\circledR} 11$. We used an inductive approach ('bottom up') for coding while a deductive approach ('top down') was used to critically reflect on and discuss identified themes in relation to the literature (Hickson 2016; Pope 2000). The coding comprised three stages. First, three interview transcripts were randomly selected and read in full several times by DO and FM. Both researchers annotated preliminary codes and then compared and discussed these among the research team to ensure that there was good agreement. Second, DO coded the full set of interview transcripts and collated them into preliminary themes. These were taken to the research team for discussion, and the data were also presented to and discussed with the international project partners. Third, themes were refined by DO and discussed with SEL, a specialist in stigma research. 
Paper accepted for publication on Ageing \& Society [20 April 2021]. ISSN: 1469-1779.

In the subsequent deductive phase, DO first engaged in-depth with the mental-health- and dementia-related stigma literature to understand and reflect upon how the study findings might fit within current relevant theories and conceptual frameworks. The analysis was informed by Link and Phelan's sociological conceptualization of stigma (Link and Phelan 2001). After initial coding, DO compared and refined identified themes with key stigma domains of the adopted concept. This process considered each theme in relation to each relevant stigma domain, and each participant story in relation to the overall data from other participants, helping the researcher to adequately collate themes into superordinate themes and name them accordingly (McCormack 2000a).

The most relevant quotes reflecting each theme were then translated into English by DO, who is proficient in both Brazilian Portuguese and English. As recommended in the literature (Regmi et al. 2010), the translated content was then checked for accuracy by another bilingual researcher (SEL), to whom English is her first language, and any disagreement with regards to wording or meaning was negotiated between the two researchers. Finally, the writing process was conducted in a reflexive way, taking themes and individual stories into account in order to develop a coherent and meaningful narrative (McCormack 2000b).

\section{Results}

\section{People living with dementia}

Two superordinate themes encompassing six themes were identified: 1 . Managing negative views of dementia; and 2. Relationships and interactions with other people (Table 3).

$<$ Insert Table 3 here $>$

\section{Managing negative views about dementia}


Paper accepted for publication on Ageing \& Society [20 April 2021]. ISSN: 1469-1779.

Participants living with dementia minimised and normalised dementia in different ways in order to make sense of and live well with dementia. This appeared to be a protective response to experiences and to their own negative notions of dementia - or internalised stigma - and to free themselves from any blame that might come from other people for having the disease. There was a sense that, by minimising or normalising dementia, participants felt people would be less inclined to think of them as being 'different' and would therefore be able to continue to treat them as before they had dementia. Another way to demonstrate this was by expressing their ability to continue to perform their day-to-day activities and to feel in control of their experiences, therefore not being someone who would be a burden to other people. Also, participants felt the needs to add the positive impacts that dementia had in their lives as a means to show that the disease might not cause only suffering or dependence as people (in their experience) might think.

One way of minimising or normalising dementia and to avoid being blamed for it was through explaining their memory problems as an inevitable part of ageing and therefore not something they could have avoided or could be blamed for. This appeared to be aligned to what participants understood from the information received from the healthcare provider at the time of 'diagnosis', probably as an attempt to legitimise the information provided to the researcher.

F13: [Doctor] said it was normal, that it was really due to age, that with time, the mind gets wasted. He said: "so much so that it is not total - you remember older things than these, so it is really a faulty memory", he said, "it's part of life".

Minimising the issue through social comparisons appeared to help participants re-establish themselves within their own contexts so they could continue to feel part of a broader group of older people.

F8: There are several older ladies nearby who are also, who are also not well, they get a bit forgetful as well. They are all old. We see that every old person does these things. 
Paper accepted for publication on Ageing \& Society [20 April 2021]. ISSN: 1469-1779.

In order to express their ability to continue to live their lives as previously and to mitigate potentially discriminatory views coming from other people, participants tried to emphasise their ability to carry out what they considered important day-to-day activities despite experiencing memory impairment.

F17: I go into town, I do my things, I go pay the bills, I go for my swimming classes, I go to church, you know? I do my things as normal. I do not owe any money to anyone... (...) Now, sometimes I forget things indeed. If I told you that I do not forget anything, I would be lying to you - however, I don't let the food get burnt.

Participants also tried to show they felt in control of their experiences and that forgetfulness was useful to protect their mental wellbeing from sad memories. F17 brought this by referring to her doctor's advice as a means to legitimise the information provided to the researcher and as being an unquestionable truth.

F17: [Doctor said] that "you get to a certain age when many people won't want to remember their past", right? So, he said: "maybe you don't want to remember what you've experienced", therefore you will simply begin to forget things that you no longer wish to remember, because if you really wanted to remember it, you would" (...) "so that's why if I say that you've got a problem, I would be lying (...); now, this problem with forgetfulness, you forget the past, because you want to live more the present".

During his interview, M22 often emphasised the positive impact of dementia in his life and it included feelings of empowerment and increased ability to do things compared to his past self.

M22: Wow, a lot different, if I was before as I am today, if my life was in the past as it is today... Because today I see things clearly. I spent my whole life not very aware of things (...) If it were like I was a while ago, I wouldn't be here giving an interview, right? [...] 
Paper accepted for publication on Ageing \& Society [20 April 2021]. ISSN: 1469-1779.

[My life] changed so much so that, if I were to do something, I would do better now than in the past. I would do it better now.

\section{Experiences when relating and interacting with others}

When relating to others, people living with dementia expressed active efforts to avoid negative reactions such as anger or judgements directed at them, like being undermined or seen as unreliable or repetitive, which could lead to feelings of shame or embarrassment. In some cases, participants demonstrated a tendency to select to whom they would disclose their diagnosis based on anticipated negative reactions that could come from this.

A few strategies used to avoid receiving negative reactions from others were to keep notes or purchasing goods with cash (rather than in instalments).

F13: (...) so that we don't keep bothering everyone: "Do you remember this? Do you remember this?" So, everything is noted down.

F17: And I no longer buy things in instalments because I fear I won't remember to pay for it. I pay for everything in cash, you know?

M22 reported his ability to remember things was undermined by family members and he tried to protect himself by arguing against it.

M22: (...) sometimes she [wife] mentions it [forgetfulness], and I say: "I am not as forgetful as you are saying".

Others felt people would not understand or be able to relate to their experiences which, in some cases, appeared to lead to 'selective disclosure' depending on whether people living with dementia felt others would be patient and empathetic (tendency to disclose), or angry and unempathetic (tendency towards non-disclosure), towards them.

F8: When we meet a relative that understands and doesn't get mad, that's okay, yes [to talk about forgetfulness]. There are people who get angry and stuff. 
Paper accepted for publication on Ageing \& Society [20 April 2021]. ISSN: 1469-1779.

F9 believed that people could judge her or look down upon her, which could then lead to her being excluded. Indeed, this participant reported later in the interview to be living in isolation.

F9: Ah it gets a bit... [long pause] I think people would distance themselves, wouldn't they? (...) We can see [reactions] in certain people, can't we? (...) I think people get a bit like... People keep kind of looking [at you], don't they?

F9: Nowadays I take care of my house, I stayed [living] alone here (...) I only stay inside my house.

There were also anticipated feelings of shame or embarrassment when experiencing forgetfulness during conversations to which participants were expected to contribute.

$R$ : Why do you fear having memory loss? What do you think this can cause?

F9: Ah we feel like... Weird, like, thinking: "wow, I am forgetful, how am I going to engage with other people", right? It is embarrassing, isn't it? (...) If someone perhaps asks, like in the old days, asks something and we do not know what to answer, right?

\section{Family carers of people living with dementia}

Four superordinate themes encompassing nine themes were identified: 1 . Views and beliefs about dementia and people living with the condition; 2. Power dynamics within caring relationships; 3. Exclusion and discrimination towards carers and people living with dementia; and 4. Essential components of caring (Table 4).

$$
<\text { Insert Table } 4 \text { here }>
$$

\section{Views and beliefs about dementia and people living with the condition}

Having a person living with dementia in the family was in most cases the first contact participants ever had with the condition, and so carers felt they lacked knowledge of dementia and experienced difficulties talking about it within their families. This appeared to 
Paper accepted for publication on Ageing \& Society [20 April 2021]. ISSN: 1469-1779.

have several consequences, such as individual blaming, stereotyping and labelling (e.g. absence of personhood), delayed diagnosis, and conflicts with the person living with dementia. Carers had difficulties to talk about dementia, either by avoiding the use of the term 'dementia' or referring to the person living with dementia using impersonal pronouns or in plural. Other people's lack of understanding of dementia led to carers feeling discredited and to feeling the need to emphasise their relatives' loss of cognitive abilities.

Not being able to distinguish the early symptoms of dementia from the person made carers less empathetic towards the feelings of the person living with dementia, which could cause distress for the person and guilt for the family carer later on. They also believed this unawareness of dementia contributed to a delay in recognition and acceptance by family members.

F7: Sometimes my mother had certain behaviours, which now I realise it could be some sort of distress, you know? But I only see this now, because at the time I didn't think about this, I didn't feel it.

F10: (...) It is difficult for you to detect, you know, that the person is [with dementia] (...). Then a person may think it is normal and when you see it is [advanced], right?

Though none of the participants were sure about the exact cause of dementia, they felt the individual often had some control over whether they developed dementia, which could potentially lead to labelling or victim blaming.

M21: I think she has always been like this, calm, and did not develop her mind. To me, that was it. She stayed at home, minding our neighbours...

F12: It's like metal, right? It gets rusty. The mind gets rusty if you don't use it enough.

Many carers said it was common for people around them to avoid using the term 'dementia', making it implicit and/or hidden in their conversations, demonstrating a shared difficulty that lay people have in talking about dementia. 
Paper accepted for publication on Ageing \& Society [20 April 2021]. ISSN: 1469-1779.

F7: It seems to me that there was a barrier. We never got to talk about it [dementia], neither between my sisters, nor with her [mother living with dementia].

Common negative perceptions about people living with dementia included: being absent, strange, emotionless, passive, incapable or manipulative, all of which were classified within a single theme labelled 'depersonalisation'. Elements of depersonalisation were present in all interviews and were most frequently associated with a sense of anticipated grief, as exemplified in the quote below.

F14: It is a shock for you to know that the person will lose her independent life, that she will no longer be that person, because Alzheimer's transforms the person, right? (...) A person, over time, will stop being, so this is bad...

More subtle communication of this depersonalisation was sometimes present in narratives through the absence of the personal pronouns (he/she) when referring to the person living with dementia. In the English language this would be equivalent to using 'it' to refer to a person, as shown below.

F5: I take [it] out, walk [it], bring [it] to the table for meals, [it] doesn't eat elsewhere. Water, I have to offer it all the time, take [it] to the bathroom.

For this participant, the depersonalisation of people living with dementia sometimes led to confusion about how to understand or interpret their feelings and even whether people living with dementia could still have valid emotions.

F5: (...) they unlearn all actions. However, I sense that [she] has feelings - she can't see me crying that she immediately gets desperate.

Many carers also felt their roles had reversed with their parents living with dementia, and they now saw them as their dependent children. This led to infantilising behaviours such as speaking like a child when talking with people living with dementia 
Paper accepted for publication on Ageing \& Society [20 April 2021]. ISSN: 1469-1779.

F7: I have a very strong connection with children (...) so I don't know if I saw my mother as a child, depending on me, you know?

F1: My brother-in-law passed away last month, and my sister decided to tell [them] as [you would do with] a child: "He went to live with baby Jesus in heaven".

Difficulties in distinguishing dementia symptoms from the individual sometimes led carers to perceive the person living with dementia as being manipulative.

F18: In front of the doctor, the person seems to change, right? It seems that they even recovered their memory. Whenever she talked to him, she did not demonstrate that she was so absent, that she had so much memory loss.

Carers often generalised people living with dementia as if 'these' individuals formed a separate societal group. This 'otherness' almost exclusively implied negative stereotypes, such as depressive, aggressive, or difficult, which also de-personalised them.

F3: I took her to the beach house, she didn't like it, she wanted to leave. They don't have peace, it's such a difficult thing, I don't know.

It was common for carers to experience disbelief from others when they spoke about their relative's dementia, which often made them feel discredited. This appeared to be due to a stereotypical view that people living with mental illness should always show their symptoms.

F5: [Neighbours] thought I was crazy. They said: "your mother-in-law has nothing. She is doing very well. Look how well she is doing". Okay, we have a diagnosis, and we are living here, seeing that something is wrong with her. "No, but she is doing very well."

Consequently, carers would sometimes highlight the person with dementia's disabilities to validate their experience and protect the person living with dementia. This was done so through narratives of lack of understanding, not being fine, or not being in control of one's own mind. 
Paper accepted for publication on Ageing \& Society [20 April 2021]. ISSN: 1469-1779.

M6: We explained [to the porter] what it [dementia] was, said that she had no understanding. That she thought she was fine, but she really wasn't. That she looked like a person in possession of her [mental] faculties, but she wasn't. So, he wasn't supposed to let her out, he shouldn't open the gate for her.

\section{Power dynamics within caring relationships}

Caring for a person with dementia involves the need to manage the challenges arising from the cognitive decline and the behavioural changes related to the progressive nature of dementia. As such, carers often felt the need to protect their relatives living with dementia from getting lost in unknown environments, physical hazards related to day-to-day activities, and financial abuse from strangers, for example. This willingness to protect commonly led to situations in which carers felt the need to exert control, demand obedience, and invade the person's privacy, all of which had good intentions but risked infringing the rights of the person living with dementia through abuse of power.

Examples of control included removing money and credit cards from their relatives living with dementia to prevent financial abuse from strangers.

F14: There are those who take advantage (...) And then they [sons] decided that it was better to take her debit card and check book from her.

Worries about the person's safety also led carers to limit their activities within the house and to limit their food intake.

F5: She always used to make coffee or something, [which was] very dangerous. We asked him [father-in-law] not to let her do anything else.

The intimate nature of caring for a person living with dementia also led carers to feel that they were invading the person's privacy, which made them feel embarrassed, particularly when physical care was needed. 
Paper accepted for publication on Ageing \& Society [20 April 2021]. ISSN: 1469-1779.

F3: I had to take her clothes off, and she had always been a private person - we never saw her panties on the clothesline. Then we began to leave her without her panties, we began to make her use diapers.

In addition, in order to avoid upsetting their relatives living with dementia, several carers withheld the dementia diagnosis and other sensitive information from them, controlling what types of information their relatives living with dementia could have access to.

F1: We began to keep this kind of information [from them], you know? We had relatives who passed away and we began to avoid telling the news to them.

In order to ensure the person living with dementia was fed and clean, several carers felt the need to establish a strict daily routine, which was often against the person with dementia's wishes and led to forceful and controlling situations.

F3: [Husband said] "(Name) eat it!", then she looked like: "But I ... but I ...", "Eat it!", then he would violently put the food in her mouth. Because "that is that time when she has to eat it" (...).

Carers also felt that the person with dementia had to be obedient, reporting several instances in which the person would 'misbehave' or not obey their orders, generating further stress for the carers.

F1: [The person] Do not obey us, you know? [They] need attention.

M6: She has gone through a complicated phase, very complicated, very reactive, tough, really cantankerous, you know? "Shall we take a shower?" "I won't"; "Let's eat", "I don't want to"; she would throw away the cloth, the towel, you know?

\section{Exclusion and discrimination towards carers and people living with dementia}

Discriminatory attitudes from friends and family members towards the person living with dementia appeared to lead carers to a progressive state of social exclusion. When asked 
Paper accepted for publication on Ageing \& Society [20 April 2021]. ISSN: 1469-1779.

what they believed to cause such situation, carers often blamed the person's living with dementia's behavioural and emotional changes, though they did not agree with it.

Carers felt that the experience of dementia deeply affected the social experiences of the entire household, with a progressive sense of social exclusion affecting all of its members.

M6: Our life changed completely [...] in the sense that friends we visited, and friends who used to come to our house, the thing kind of stopped.

Carers considered that the repetitive questions from the person living with dementia were not easy to manage and that only those who had some level of care responsibility towards the person would be required to answer appropriately.

F14: [People] move away because she would call people, she would call us 22 times on the same day to ask the same question - 22. It is not easy for you to answer politely, patiently, 22 times the same thing - it is not, sorry, it is not easy. Sometimes, you feel like... you hold back because you know the person... But can you imagine it with a friend? [They] have no obligation! I have an obligation, I take a deep breath, I answer etc., but what about who doesn't?

In other instances, social exclusion was more directly enforced by members of the public in order to 'protect' other people from the undesirable behaviours of the person living with dementia.

F18: He had quite an exacerbated sexual behaviour and he began to grab the women in the water [swimming classes], and one of the ladies didn't take it very well, and the teacher said: "I think you shouldn't bring him again while he is in this phase".

As the dementia progressed, carers believed family members and friends became less inclined to engage in conversation with the person living with dementia because they were no 
Paper accepted for publication on Ageing \& Society [20 April 2021]. ISSN: 1469-1779.

longer recognised by the person, which appears to be an important attribute to establish a dialogue.

F5: But the grandchildren don't come visit either. When their grandpa was still alive, they would come from time to time, on birthdays, at Christmas, because grandpa was very affectionate, he called everyone every day, he liked talking. He could talk to the youngest, to the oldest. It was very different from the grandmother who can no longer have a chat.

F12 criticised the shunning attitudes from people, which she considered to be dehumanising towards people living with dementia, including her mother.

F12: I think when the person is well, they [people] can be interested in talking a little bit; but they soon notice that it's a little bit like that, and they no longer bother. [pause] It's a lot like a piece of furniture that you change here and there, don't pay too much attention to it.

\section{Essential components of caring}

In complex dynamics of caring relationships, particularly involving cognitive decline of the person cared for, stigmatising attitudes and beliefs do not appear to be exclusive, in the sense that positive attitudes towards the person living with dementia also co-exist. We found a polarization of positive and negative social experiences towards people living with dementia, with many carers providing elements of both sides of the spectrum. Many carers tried to provide the best care they could, with the limited resources and training they had, and their positive attitudes frequently emerged during the interviews.

The quote below from F7 provides an overall representation of the concepts identified throughout the narratives from other participants, including respect, affection, and empathy.

F7: I think the first thing to help the person is to have respect for her/him. Respect, affection, love, and care help a lot, but respect should come first. Putting the person 
Paper accepted for publication on Ageing \& Society [20 April 2021]. ISSN: 1469-1779.

with Alzheimer's in a difficult situation, such as asking: "what's his name? don't you know it anymore?!" I find it very embarrassing for a person with this type of disease, I find it very sad. I think there needs to be a lot of respect for a person with Alzheimer's. (...) Sometimes you are talking about a person in front of her making certain comments that, I put myself in the person's shoes, it must be very embarrassing. I think that all of this would need think about, people need to learn to have this respect and this care for the person.

Carers found it important for the person living with dementia to be able to keep his/her selfcare routines. As the person with dementia was often no longer able to do it independently, the carers would book or plan such activities on the person's behalf.

F14: Small things - she always liked getting her nails done; so, it doesn't matter if she no longer knows that her nails are done, the manicure comes with the same periodicity, you know. We try to provide her with these things.

There was also a preoccupation towards providing people living with dementia with activities that could stimulate, entertain, and help them to continue to be as active as possible.

F7: Here, at my house, she would stay with me during the day, and I, whatever I was going to do, I would involve her.

M6: I've done a lot of dictation with my mother, a lot of colouring with my mother. My mother always did a lot of crossword puzzles. At the beginning, we tried to encourage her to continue, to continue, to continue, until she couldn't do it anymore [...]

Carers also felt the need to be mindful about promoting the activities which were particularly of interest for the person living with dementia.

M6: "Does she like music?" Put the song on with the lyrics written underneath. Then, she follows with the karaoke... 
Paper accepted for publication on Ageing \& Society [20 April 2021]. ISSN: 1469-1779.

\section{Discussion}

This is the first qualitative study to explore the experiences, attitudes, and beliefs in relation to dementia among family carers and people living with this condition in Brazil. Dementia was commonly viewed by people living with dementia as a typical ageing issue and carers reported low levels of knowledge and awareness. People living with dementia minimised and normalised their dementia in order to adapt, build acceptance, find meaning and flourish through dementia. The 'normalisation' of memory loss was often legitimised by using the information received from their healthcare providers. Individuals living with dementia also reported experiences of social isolation and fear of being viewed as unreliable, which commonly led to selective disclosure of their diagnosis and experiences due to fear of negative reactions or exclusion. Carers considered their loved ones as being passive recipients of care, in need of their protection and decisions, which worked as a strategy to validate their own caring experiences, rather than to cause any harm. In doing so, however, carers ended up underestimating the capacities of the person living with dementia, depersonalising them as individuals, and restricting the person's freedom. Carers' expectation that people living with dementia should 'behave obediently' reflected an exasperated attempt to have the person's neuropsychiatric symptoms under control, rather than exert power over their loved ones.

Most literature on dementia-related stigma focuses on knowledge and awareness, with very little on individual experiences. Our findings overlap with misperceptions found in other studies about dementia being part of 'normal' aging (Farina et al. 2020; Ibanez et al. 2020). which in our study appeared to be used by people living with dementia as a means to manage the negative views of dementia, both external and internalised ones - i.e., minimising and normalising the issue. In addition, people living with dementia actively tried to focus on their current abilities and used aiding strategies to avoid being seen as unreliable. These also appeared to help participants to avoid being 'othered' and the associated consequences of exclusion. Studies show that such strategies could help promote a sense 
Paper accepted for publication on Ageing \& Society [20 April 2021]. ISSN: 1469-1779.

of control and self-worth in people living with mild to moderate dementia (Robinson et al. 2005; Steeman et al. 2007), which have also been considered acts of 'resistance towards social disenfranchisement' and as means of 'value attribution to self', rather than denial, in a process of reconstructing identity (Beard and Fox 2008; Mitchell et al. 2013). As the dementia progresses, and individuals may no longer be able to adapt to such social situations, disempowerment, low self-worth, and social isolation might occur (Brossard 2017).

Fear of being seen as unreliable was also identified in relation to diagnosis disclosure as some felt this information was discredited by other people's comments as if they were 'too well to have dementia'. Carers reported similar experiences whenever they tried to discuss their relatives' diagnosis with others. Though often meaning well, the negative views about a person who has dementia conveyed through discrediting attitudes can be potentially reinforced and internalised by the stigmatised, causing individuals to experience the negative consequences of self-stigma later on (ADI 2019). We found that people living with dementia were more inclined to talk about their diagnosis with people who were more empathetic and would not "be mad" at them. Studies show that concealment is also commonly used by people with other stigmatised conditions to cope with social stigma and this can have positive and negative effects on the person's wellbeing (Elliott and Doane 2015; Quinn et al. 2017). A global survey showed that concealment and secrecy related do dementia were common across various population groups in different countries and cultures. Nonetheless, a significant majority of people with dementia (86.3\%) said that people should not hide their diagnosis (ADI 2019). This suggests that while disclosure is felt to be important, fear of negative social repercussions and internalised stigma inhibits discussion.

Due to feeling discredited, carers felt the need to emphasise the person with dementia's impairment to validate their own experiences. Depersonalising views were also common and appeared to be linked to social exclusion from other family members and friends who often 
Paper accepted for publication on Ageing \& Society [20 April 2021]. ISSN: 1469-1779.

implied visiting or speaking to people living with dementia was not 'worth' it. Besides social isolation, abandonment by family and friends appeared to increase the sense of burden on carers, which further and indirectly impacted people living with dementia. For example, some carers believed that people stayed away because of the attitudes and behaviours of the person living with dementia. Justifying other people's social exclusion through blaming the stigmatised is a common discriminatory behaviour and could lead to internalised stigma in people living with dementia. A global survey showed that people living with dementia commonly feel "avoided", "ignored" and "ostracised" in their social life due to having dementia, calling it "the friendship divorce" (ADI 2019 p.14). If experienced for long periods of time, such issues could have detrimental effects on the self-worth, wellbeing, and social participation of people living with dementia (Brannelly 2011; O'Connor et al. 2018). Social isolation also deeply affects carers and may contribute to increased feelings of loneliness, social isolation, burden, and lack of support (ADI 2019).

A strong sense of duty appeared to make carers feel the need to protect their relatives living with dementia from harm by restricting their agency, demanding obedience, withholding information, and invading their privacy. These demonstrate that caring for someone with dementia embeds small acts of power which can be difficult to mitigate due to the intimate and long-lasting nature of care and responsibility (Walsh 2019). As pointed out by Link and Phelan (Link and Phelan 2014), power is used in social relationships 'to keep people down, in or away' with a purpose to benefit the stigmatiser. We found that carers sometimes tried to keep themselves and people living with dementia 'in' to maintain some social control, their own saving face, and inclusion. Walsh (2019 p.1) posits that such power may stem "not from the possession of power itself but from the very nature of caring relationships", arguing that the "caring itself, rather than the malign influence of power dynamics", may generate "a risk of unintentional abuse". Such dynamics did not seem purposively malign; however, there might be a risk that this power could be abused and become a moral concern in caring for a person living with dementia. 
Paper accepted for publication on Ageing \& Society [20 April 2021]. ISSN: 1469-1779.

We do not attempt to excuse, nor to judge carers for their probably unintended stigmatising behaviours and attitudes towards people living with dementia, but to highlight the complexity of the caring role and the emotional skills it requires. The threads of the social tissue are well knotted, and the stigma cascade is a part of a complex network of discourses and practices (Link and Phelan 2014). Our findings show an enormous willingness of carers to provide care involving respect, empathy, and love, respecting the wishes of the person living with dementia and their personhood. Carers did so with little information and voluntarily identified ways through which their relatives living with dementia could continue to contribute for as long as possible to the family routines and social activities.

\section{Strengths and limitations}

This is a novel research study that brought to light both subtle and explicit stigmatising experiences that people living with dementia and carers endure on their day-to-day lives in Brazil. Exploring both groups' experiences in the same paper helped highlight the possible relationship dynamics between dyads of family carers and people living with dementia, helping build a better understanding of how carers' potentially stigmatising attitudes and behaviours might be 'received' by the group of people living with dementia, giving a wider perspective to this phenomenon. Individuals from different socioeconomic and educational backgrounds took part and showed that dementia awareness, knowledge, attitudes, and behaviours towards dementia appear similar across these groups.

Social class, ethnicity, and social inequality could be related to how participants, for example, internalised ableism and/or normalised their health-related circumstances and limitations. For example, those living in low-income households with restricted access to health care and support may have normalised certain unfair experiences and may not have considered them to be discrimination. As our sample was small, we were not able to explore these issues in depth with participants and thus, this is an important area for future research. 
Paper accepted for publication on Ageing \& Society [20 April 2021]. ISSN: 1469-1779.

Further, identifying people living with mild to moderate dementia locally was difficult as the majority of people in Brazil receive their diagnosis later on in their disease trajectory, and so the sample size of people living with dementia was small, making it challenging to establish theoretical saturation. Finally, only one spouse and one male person living with dementia were interviewed; future studies should seek to recruit samples with wider characteristics.

\section{Implications}

The complexity of the social experience of dementia and the 'fine lines' between being a good carer and being a 'stigmatiser' demonstrate the need for continuous support for carers and people living with dementia. Carers in Brazil are mostly unsupported and nearly all care is provided by families. We argue that support and training in person-centred and ethical care could help carers make sense of their experiences in a way that would also respect the rights and personhood of the person living with dementia. Anti-stigma interventions for the wider community could have an important impact on the lives of carers and people living with dementia through e.g., reducing carer burden, discrimination, social exclusion. Anti-stigma campaigns might be effective to mitigate misrepresentations and myths about dementia, as well as the use of stigmatized language and stereotypical views. Such interventions should be driven by and address issues identified as important among those with lived experience.

Our findings also contribute to further understanding how caring relationships can be potentially stigmatising and to the development of theoretical developments on dementiarelated stigma. We found that depersonalisation, low levels of awareness, issues of control, obedience, social exclusion, isolation, and concealment are key stigmatising among these groups. Future research should further explore such issues using different research methods and study designs in order to establish the extent and magnitude of such experiences and their impact on the wellbeing and life chances of people living with dementia. In addition, the relationship between socioeconomic status and experiences of stigma and discrimination should be further explored among people living with dementia and carers. The views of other 
Paper accepted for publication on Ageing \& Society [20 April 2021]. ISSN: 1469-1779.

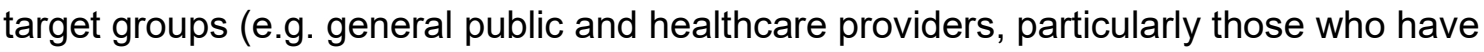

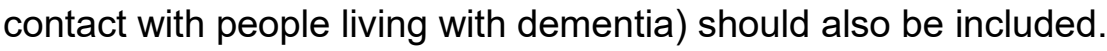

\section{Conclusions}

Through this qualitative study conducted in Sao Paulo, Brazil, we showed that stigma and

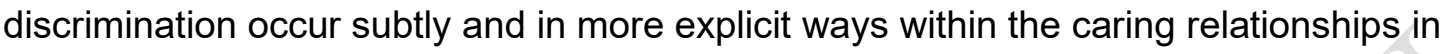

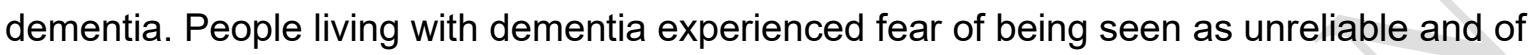

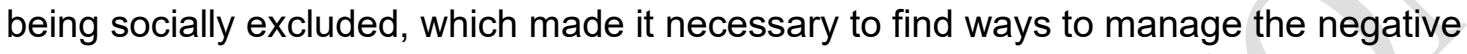
experiences. Carers showed a strong willingness to provide good care, to protect the person living with dementia, as well as to understand and validate their own experiences. In doing so, however, carers ended up depersonalising and infantilising people living with dementia, underestimating their capacities, demanding 'obedience', and restricting the person's freedom. Carers strongly valued empathy, patience, affection, and respect as key

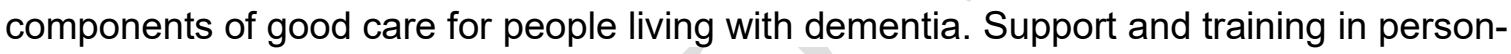
centred care might facilitate the quality of informal care, whilst preserving the agency, personhood and rights of people living with dementia. Targeted anti-stigma efforts could help reduce negative views towards dementia, which could help mitigate social isolation and concealment for the person living with dementia, while reducing carer burden and

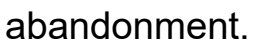

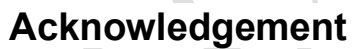

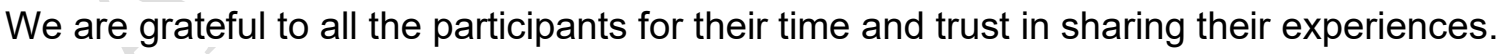

\section{Funding}

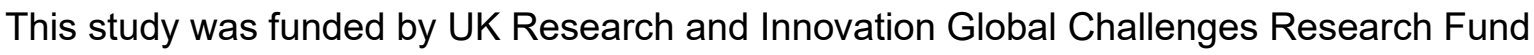
(ES/P010938/1).

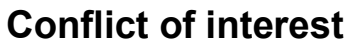


Paper accepted for publication on Ageing \& Society [20 April 2021]. ISSN: 1469-1779.

The authors declare no conflict of interest.

\section{References}

Alzheimer Disease International 2019. World Alzheimer Report 2019: Attitudes to dementia.

Alzheimer's Disease International 2015. The Global Impact of Dementia: An analysis of prevalence, incidence, cost and trends updates.

Beard, R. L. and Fox, P. J. 2008. Resisting social disenfranchisement: Negotiating collective identities and everyday life with memory loss. Social Science \& Medicine, 66, 7, 1509-20.

Blay, S. L. and Peluso, E. T. P. 2010. Public stigma: The community's tolerance of Alzheimer disease. A. Angermeyer Bhugra, Bhugra, Blay, Brockington, Corrigan, de Toledo, de Toledo, de Toledo, Gureje, Haghighat, Jeste, Jorm, Lauber, Link, Mak, Peluso, Peluso, Roberts, Rusch, Taskin, Veloski, Wadley, Werner, Werner, Werner, Werner, Wolff, Wolff (ed). The American Journal of Geriatric Psychiatry, 18, 2, 163-71.

Blay, S. L. and Peluso, E. T. P. 2008. The public's ability to recognize Alzheimer disease and their beliefs about its causes. A. Angermeyer Angermeyer, Angermeyer, Ayalon, Blay, Corrigan, Fisher, Giosan, Guarnaccia, Gureje, Haslam, Hinlon, Jorm, Jorm, Leventhal, Link, Mulatu, Murphy, Nakane, Narikiyo, Nutbeam, Peluso, Reed, Roberts, Roberts, Werner, Werner, Werner, Werner (ed). Alzheimer Disease and Associated Disorders, 22, 1, 79-85.

Brannelly, T. 2011. Sustaining citizenship: people with dementia and the phenomenon of social death. Nursing ethics, 18, 5, 662-71.

Brossard, B. 2017. Losing credibility. In Forgetting Items: The Social Experience of Alzheimer's Disease. Indiana University Press, 35-70.

Chase, S. 2018. Narrative inquiry: Toward theoretical and methodological maturity. In The Sage handbook of qualitative research. SAGE, Thousand Oaks, CA, 546-60. 
Paper accepted for publication on Ageing \& Society [20 April 2021]. ISSN: 1469-1779.

Dementia Australia 2018. Dementia Language Guidelines.

Elliott, M. and Doane, M. J. 2015. Stigma Management of Mental Illness: Effects of Concealment, Discrimination, and Identification on Well-Being. Self and Identity, 14, 6, 654-74.

Fagundes, S. D., Silva, M. T., Thees, M. F. R. S. and Pereira, M. G. 2011. Prevalence of dementia among elderly Brazilians: a systematic review. Sao Paulo Medical Journal, 129, 1, 46-50.

Farina, N., Suemoto, C. K., Burton, J. K., Oliveira, D. and Frost, R. 2020. Perceptions of dementia amongst the general public across Latin America: a systematic review. Aging \& Mental Health, 1-10.

FEBRAZ 2019. Instituto Não Me Esqueças. http://www.naomeesquecas.com.br/ Available online at http://www.naomeesquecas.com.br/conteudo/ [Accessed 15 June 2019].

Fletcher, J. R. 2019. Destigmatising dementia: The dangers of felt stigma and benevolent othering. Dementia, 147130121988482.

Giacomin, K. C., Duarte, Y. A. O., Camarano, A. A., Nunes, D. P. and Fernandes, D. 2018a. Care and functional disabilities in daily activities - ELSI-Brazil. Rev. Saúde Pública, 52, Suppl 2.

Giacomin, K. C., Duarte, Y. A. O., Camarano, A. A., Nunes, D. P. and Fernandes, D. 2018b. Care and functional disabilities in daily activities - ELSI-Brazil. Rev. Saúde Pública, 52, Suppl 2.

Goffman, E. 1963. Stigma: Notes on the management of spoiled identity. Simon and Schuster, New York, NY.

Hatzenbuehler, M. L., Phelan, J. C. and Link, B. G. 2013. Stigma as a Fundamental Cause of Population Health Inequalities. American Journal of Public Health, 103, 5, 813-21.

Herrmann, L. K., Welter, E., Leverenz, J., Lerner, A. J., Udelson, N., Kanetsky, C. and Sajatovic, M. 2018. A Systematic Review of Dementia-related Stigma Research: Can We Move the Stigma 
Paper accepted for publication on Ageing \& Society [20 April 2021]. ISSN: 1469-1779.

Dial?. The American journal of geriatric psychiatry : official journal of the American Association for Geriatric Psychiatry, 26, 3, 316-31.

Hickson, H. 2016. Becoming a critical narrativist: Using critical reflection and narrative inquiry as research methodology. Qualitative Social Work: Research and Practice, 15, 3, 380-91.

Ibanez, A., Flichtentrei, D., Hesse, E., Dottori, M., Tomio, A., Slachevsky, A., Serrano, C. M., Gonzalez-Billaut, C., Custodio, N., Miranda, C., Bustin, J., Cetckovitch, M., Torrente, F., Olavarria, L., Leon, T., Beber, B. C., Bruki, S., Suemoto, C. K., Nitrini, R., Miller, B. L. and Yokoyama, J. S. 2020. The power of knowledge about dementia in Latin America across health professionals working on aging. Alzheimer's \& Dementia: Diagnosis, Assessment \& Disease Monitoring, 12, 1.

Kitwood, T. 2006. Malignant social psychology. In Understanding care, welfare and community a reader. Routledge, London; New York.

Link, B. G. and Phelan, J. 2014. Stigma power. Social Science \& Medicine, 103, 24-32.

Link, B. G. and Phelan, J. C. 2001. Conceptualizing Stigma. Annual Review of Sociology, 27, 1, 36385.

Lopez, R. P., Rose, K. M., Kenney, L., Sanborn, V. and Davis, J. D. 2019. Managing Shame: A Grounded Theory of How Stigma Manifests in Families Living With Dementia. Journal of the American Psychiatric Nurses Association, 9507418, 1078390319832965.

Marques, M. L., da Silva, M. C. and de Camargo, D. 2017. Spacial Analysis of Socio-Environmental Vulnerability in Campinas, SP, Brazil. Revista Brasileira de Cartografia, Edição Especial Geotecnologias e Desastres Naturais: $\mathbf{N}^{\circ}$ 69/9, 1711-23.

McCormack, C. 2000a. From Interview Transcript to Interpretive Story: Part 1-Viewing the Transcript through Multiple Lenses. Field Methods, 12, 4, 282-97. 
Paper accepted for publication on Ageing \& Society [20 April 2021]. ISSN: 1469-1779.

McCormack, C. 2000b. From Interview Transcript to Interpretive Story: Part 2- Developing an Interpretive Story. Field Methods, 12, 4, 298-315.

Mitchell, G. J., Dupuis, S. L. and Kontos, P. 2013. Dementia Discourse: From Imposed Suffering to Knowing Other-Wise. Journal of Applied Hermeneutics, 2013.

Mizock, L. and Russinova, Z. 2015. Intersectional Stigma and the Acceptance Process of Women with Mental Illness. Women \& Therapy, 38, 1-2, 14-30.

Nakamura, A. E., Opaleye, D., Tani, G. and Ferri, C. P. 2015. Dementia underdiagnosis in Brazil. The Lancet, 385, 9966, 418-19.

Nguyen, T. and Li, X. 2020. Understanding public-stigma and self-stigma in the context of dementia: A systematic review of the global literature. Dementia, 19, 2, 148-81.

O’Connor, D., Mann, J. and Wiersma, E. 2018. Stigma, discrimination and agency: Diagnostic disclosure as an everyday practice shaping social citizenship. Journal of Aging Studies, 44, $45-51$.

Pope, C. 2000. Qualitative research in health care: Analysing qualitative data. $B M J, 320,7227,114-$ 16.

Prince, M., Wimo, A., Guerchet, M., Ali, G.-C., Wu, Y.-T. and Prina, A. M. 2015. World Alzheimer Report 2015: The Global Impact of Dementia - An analysis of prevalence, incidence, cost and trends. London.

Quinn, D. M., Weisz, B. M. and Lawner, E. K. 2017. Impact of active concealment of stigmatized identities on physical and psychological quality of life. Social Science \& Medicine, 192, 14 17. 
Paper accepted for publication on Ageing \& Society [20 April 2021]. ISSN: 1469-1779.

Regmi, K., Naidoo, J. and Pilkington, P. 2010. Understanding the Processes of Translation and Transliteration in Qualitative Research. International Journal of Qualitative Methods, 9, 1, $16-26$.

Robinson, L., Clare, L. and Evans, K. 2005. Making sense of dementia and adjusting to loss: Psychological reactions to a diagnosis of dementia in couples. Aging \& Mental Health, 9, 4, $337-47$.

Rüsch, N., Angermeyer, M. C. and Corrigan, P. W. 2005. Mental illness stigma: Concepts, consequences, and initiatives to reduce stigma. European Psychiatry, 20, 8, 529-39.

Steeman, E., Godderis, J., Grypdonck, M., De Bal, N. and De Casterlé, B. D. 2007. Living with dementia from the perspective of older people: Is it a positive story? Aging \& Mental Health, 11, 2, 119-30.

Swaffer, K. 2014. Dementia: stigma, language, and dementia-friendly. Dementia (London, England), 13, 6, 709-16.

Walsh, J. 2019. Caregiving and the Abuse of Power. Feminist Philosophy Quarterly, 5, 3, 1-21.

Werner, P. 2014. Stigma and Alzheimer's disease: A systematic review of evidence, theory, and methods. The stigma of disease and disability: Understanding causes and overcoming injustices., 223-44.

Young, J. A., Lind, C., Orange, J. B. and Savundranayagam, M. Y. 2019. Expanding current understandings of epistemic injustice and dementia: Learning from stigma theory. Journal of Aging Studies, 48, 76-84.

Zimmermann, M. 2017. Alzheimer's Disease Metaphors as Mirror and Lens to the Stigma of Dementia. Literature and medicine, 35, 1, 71-97. 
Paper accepted for publication on Ageing \& Society [20 April 2021]. ISSN: 1469-1779.

Table 1. Stigma and discrimination domains covered in the interview topic guide

\section{Domains discussed}

- Experiences of having dementia or caring for someone with dementia

- Local idioms and language used to talk about dementia

- Knowledge, attitudes, and behaviour towards people living with dementia and their carers

- Current practices to promote social inclusion and thoughts and preferences about how we can reduce stigma and create more inclusive communities 
Table 2. Sociodemographic characteristics of participants

\begin{tabular}{|c|c|c|}
\hline & $\begin{array}{l}\text { People living with dementia }(n=6) \\
n(\%)\end{array}$ & $\begin{array}{c}\text { Unpaid carers }(n=15) \\
n(\%)\end{array}$ \\
\hline Age (mean; range) & $80 ; 73-87$ & $58(46-86)$ \\
\hline Gender (female) & $5(83.3)$ & $10(66.7)$ \\
\hline Ethnicity (white) & $5(83.3)$ & $12(80.0)$ \\
\hline \multicolumn{3}{|l|}{ School attainment } \\
\hline Illiterate & $2(33.3)$ & 0 \\
\hline $1-4$ years & $2(33.3)$ & $2(13.3)$ \\
\hline $5-8$ years & $2(33.3)$ & $5(33.3)$ \\
\hline $9+$ years & 0 & $8(53.3)$ \\
\hline \multicolumn{3}{|l|}{ Civil status } \\
\hline Single & 0 & $2(13.3)$ \\
\hline Married & $2(33.3)$ & $9(60.0)$ \\
\hline Separated/Divorced & $1(16.7)$ & $4(26.7)$ \\
\hline Widowed & $3(50.0)$ & 0 \\
\hline \multicolumn{3}{|l|}{ Socioeconomic sector of residence* } \\
\hline Low & $3(50.0)$ & $8(53.3)$ \\
\hline Middle-Low & $1(16.7)$ & $1(6.7)$ \\
\hline Middle-High & $2(33.3)$ & $6(40.0)$ \\
\hline \multicolumn{3}{|l|}{ Occupation } \\
\hline Formal paid job & 0 & $8(53.3)$ \\
\hline Informal job / Left job to care & 0 & $1(6.7)$ \\
\hline Unemployed / Left job to care & 0 & $1(6.7)$ \\
\hline Retired and has an informal/formal job & 0 & $3(20.0)$ \\
\hline Retired and does not work & $6(100)$ & $2(13.3)$ \\
\hline \multicolumn{3}{|l|}{ Relationship to the person with dementia } \\
\hline Son/Daughter & - & $10(66.7)$ \\
\hline Daughter in law & - & $3(20.0)$ \\
\hline Spouse & - & $1(6.7)$ \\
\hline
\end{tabular}

${ }^{*}$ As we did not ask participants directly about their socio-economic group, we categorised individuals based on their socioeconomic sector of residence, according to Marques et al., (2017). 
Paper accepted for publication on Ageing \& Society [20 April 2021]. ISSN: 1469-1779.

Table 3. Stigmatising experiences identified in interviews with people living with dementia

\section{Superordinate themes}

1. Managing negative views of dementia

2. Negative experiences when relating and interacting with others

\section{Themes}

- Minimising and normalising dementia and symptoms

- Emphasising the ability to live an active life

- Expressing the positive impacts of dementia in one's life

- Fear of negative reactions

- Selective disclosure of diagnosis and personal experiences 
Paper accepted for publication on Ageing \& Society [20 April 2021]. ISSN: 1469-1779.

Table 4. Stigmatising experiences, attitudes, and behaviours related to dementia identified in interviews with unpaid carers

\section{Superordinate themes}

1. Views and beliefs about dementia and people living with the condition

2. Power dynamics within caring relationships

3. Exclusion and discrimination towards carers and people living with dementia

4. Essential components of caring

\section{Themes}

- (Un)Awareness of and (mis)beliefs about dementia

- Depersonalisation

- Emphasis on loss of capacity

- Control, protection, and agency

- Demanding obedience

- Social exclusion and abandonment

- Blaming the person living with dementia

- Individual and interpersonal aspects of care

- Activity and participation 